\title{
EFFECT OF COBALT AND TITANIUM ADDITIONS ON CORROSION AND WEAR RESISTANCE OF NICKEL CONTAINING ALUMINUM BRONZES
}

\author{
Aleattin KULAKLI, Fikri Erdem ŞEŞEN, Talip ÇITRAK, Tuba ÖZEREN \\ Sağlam Metal San. ve Tic. A.Ş., Kocaeli, Turkey, \\ aleattin.kulakli@saglammetal.com, arge@saglammetal.com, arge@saglammetal.com, \\ tuba.ozeren@saglammetal.com
}

https://doi.org/10.37904/metal.2020.3616

\begin{abstract}
CuAl10Ni5Fe4 aluminum bronzes have better corrosion resistance and higher wear resistance at high temperatures compared to other copper alloys. In this study, the effect of cobalt (Co) and titanium (Ti), which were added in the amount of $0.5 \%$ as a grain refiner, on the properties of nickel-containing aluminum bronze (CuAl10Ni5Fe4 alloy) was investigated in cast and forged conditions. The alloys were produced by melting scrap in a metal induction furnace, pouring molten metal into a mould made of steel and hot forging processes. In order to examine the effect of grain refiners on the phase structure of the alloys, microstructural examination was also conducted. Microhardness and mechanical properties were measured using the relevant test devices. Potentiodynamic corrosion tests were performed in a neutral $\mathrm{NaCl}$ solution to determine the corrosion rates of the forged alloys. Furthermore, wear behaviour of alloys under a $40 \mathrm{~N}$ load was investigated. It has emerged from the general results that cobalt and titanium elements are highly effective in grain size reduction, leading to an improvement in the mechanical properties, corrosion and wear resistance of the CuAl10Ni5Fe4 alloy.
\end{abstract}

Keywords: Aluminum bronze, grain refining element, hot forging, potentiodynamic corrosion test, wear test

\section{INTRODUCTION}

Nickel containing aluminum bronzes are one of the most widely used materials owing to their high mechanical strength, wear resistance and corrosion resistance [1]. Nickel containing aluminum bronzes also contain iron, manganese and/or silicon [2]. Possessing high mechanical strength, superior elasticity and good absorption capacity, as well as exhibiting good corrosion and wear resistance, place these alloys among the most useful engineering materials [3].

Nickel containing aluminum bronzes have a complex structure. Typical as-cast microstructure is composed of soft, copper-rich $\alpha$ (alpha) phase, hard, martensitic $\beta$ (beta) phase and several hard, intermetallic $\kappa$ (kappa) phases ( $\kappa_{1}, \kappa_{\mathrm{II}}, \kappa_{\mathrm{II}}$ and $\kappa_{\mathrm{IV}}$ ) [4]. Mechanical properties and abrasive behaviour of nickel containing aluminum bronzes greatly depend on their microstructure. Hardness and tensile strength are increased but percent elongation tends to be decreased as the volume ratio of soft $\alpha$ phase is reduced and the volume ratios of hard $\kappa$ phases are increased [5].

Results of many researches that were carried out to improve mechanical strength and wear resistance of nickel aluminum bronzes have been reported in the literature. Several studies related to the effect of exterior factors such as the lubricating medium and the working environment on tribological behaviours of bronzes are available. However, only a small number of studies about the effects of basic properties like chemical composition and microstructure of the alloy, volume ratio of the soft phase to the hard phase and average grain size have been performed. These factors are essential in designing the engineering materials. 
Throughout investigations have been performed about corrosion behaviour of bronzes having an aluminum content less than $9.4 \%$. When Al- $\alpha$ bronzes are subjected to corrosion in a salty water, phases of $\alpha, \beta$ and $\gamma_{2}$ exhibit different degrees of resistance against corrosion in $\mathrm{NaCl}$ solution. It has been reported that $\alpha$ phase is more stable than $\beta$ and $\gamma_{2}$ phases [6], but no study seems to be accomplished about the effect of grain refiner addition on corrosion properties of these alloys.

Especially industries such as defense and aviation use high value-added products from aluminum bronzes in various fields. Alloys used in these industries are expected to have much higher abrasion and corrosion resistance and minimum casting defects in order to be used for a longer period of time. Therefore, in this study the aim was to manufacture, as an option to the currently available aluminum bronzes, products with higher characteristics and quality as demanded by such industries. For this purpose, one of the projects designed in our R\&D Center is to examine the effect of grain reducing elements on the performance and production processes of these alloys.

Effect of cobalt and titanium, which were added as grain refiners in the content of $0.5 \mathrm{wt} \%$, on properties of CuAl10Ni5Fe4 alloy in as-cast and forged condition was investigated in this work. The alloys were produced through melting of metal scrap in a laboratory-scale induction furnace, pouring the melt into a mould made of steel and hot forging. Microstructure of the samples was investigated in order to visualise the phase structures of the alloys and measure the grain size. Hardness values and mechanical properties were evaluated by utilising the related test devices. A potentiodynamic corrosion test was conducted in a neutral $\mathrm{NaCl}$ solution in order to measure the corrosion resistance of the forged alloys. Also, wear resistances of the alloys under a load of $40 \mathrm{~N}$ were measured at room temperature.

\section{EXPERIMENTAL PROCEDURE}

Chemical composition analyses of the studied alloys are given in Table 1. A standard CuAl10Ni5Fe4 alloy was used as the reference material.

Table 1 Chemical composition of the cast aluminum bronzes

\begin{tabular}{|c|c|c|c|c|c|c|c|}
\hline \multirow{2}{*}{ Sample } & \multicolumn{7}{|c|}{ Chemical composition (wt\%) } \\
\cline { 2 - 8 } & $\mathbf{C u}$ & Al & $\mathbf{~ N i}$ & $\mathbf{F e}$ & $\mathbf{M n}$ & Co & $\mathbf{T i}$ \\
\hline Alloy 1 & 81.0 & 9.8 & 5.1 & 3.0 & 0.8 & - & - \\
\hline Alloy 2 & 80.5 & 10.3 & 4.4 & 3.2 & 0.8 & 0.5 & - \\
\hline Alloy 3 & 81.5 & 9.9 & 4.5 & 3.1 & 0.7 & - & 0.5 \\
\hline
\end{tabular}

Charges each of which weighted $10 \mathrm{~kg}$ were melted in a $15 \mathrm{~kg}$ capacity open atmosphere induction furnace and poured into a cylindrical mould made of steel. Cylindrical ingots having $68 \mathrm{~mm}$ diameter and $120 \mathrm{~mm}$ length were obtained.

After surface trimming, the cleaned ingots were held in an annealing furnace at $875^{\circ} \mathrm{C}$ for 1 hour prior to being shaped into bars with a cross-section of $16 \mathrm{~mm} \times 16 \mathrm{~mm}$ by hot forging.

Vickers microhardness values of all samples, either as-cast or forged, were measured by using a Future-Tech FM800e microhardness tester under a load of $1000 \mathrm{gf}$. Microstructural investigations of all as-cast and forged samples were performed by utilising a Nikon Eclipse MA100 optical microscope after polishing and chemical etching of these samples. Micro-scale chemical etching of the samples were provided by immersion into 100 $\mathrm{ml}$ distilled water containing $50 \mathrm{ml} \mathrm{HCl}, 10 \mathrm{ml} \mathrm{HNO}_{3}$ and $10 \mathrm{~g} \mathrm{FeCl}_{3}$.

Potentiodynamic corrosion test was applied to the forged samples. $\mathrm{Ag} / \mathrm{AgCl}$ was used as the reference electrode while the counter electrode was a pair of graphite rods. Samples having dimensions of $33 \mathrm{~mm} \times 18$ $\mathrm{mm} \times 10 \mathrm{~mm}$, together with the electrodes, were immersed into the corrosive environment that was generated 
by adding $\mathrm{NaCl}$ in the content of $3.5 \%$ into distilled water and held in this solution at room temperature for 1800 seconds. Corrosion rates of the samples were calculated in accordance to ASTM G102-89 by the aid of weight loss values [7]. In addition to the corrosion experiments, the samples were subjected to wear test at room temperature under a load of $40 \mathrm{~N}$ in accordance to ASTM G99 [11]. Test parameters were determined as $20 \mathrm{~mm}, 500 \mathrm{~m}$ and $120 \mathrm{~mm} / \mathrm{s}$ for impingement distance, sliding distance and sliding velocity respectively while a $6 \mathrm{~mm}$ diameter ball made of 1040 steel was used as the abrasive material.

\section{EXPERIMENTAL RESULTS}

\subsection{Microstructural investigations}

Average grain size values of the samples obtained from as-cast ingots are given in Table 2. Measurements performed by using the optical microscope revealed that additions of cobalt and titanium decreased the grain size of the alloy by $40-60 \%$.

Table 2 Average grain sizes of the alloys

\begin{tabular}{|c|c|c|}
\hline Sample & Average grain length $(\boldsymbol{\mu m})$ & Average grain width $(\boldsymbol{\mu m})$ \\
\hline Sample 1 & 708 & 566 \\
\hline Sample 2 (Co added) & 445 & 292 \\
\hline Sample 3 (Ti added) & 314 & 178 \\
\hline
\end{tabular}
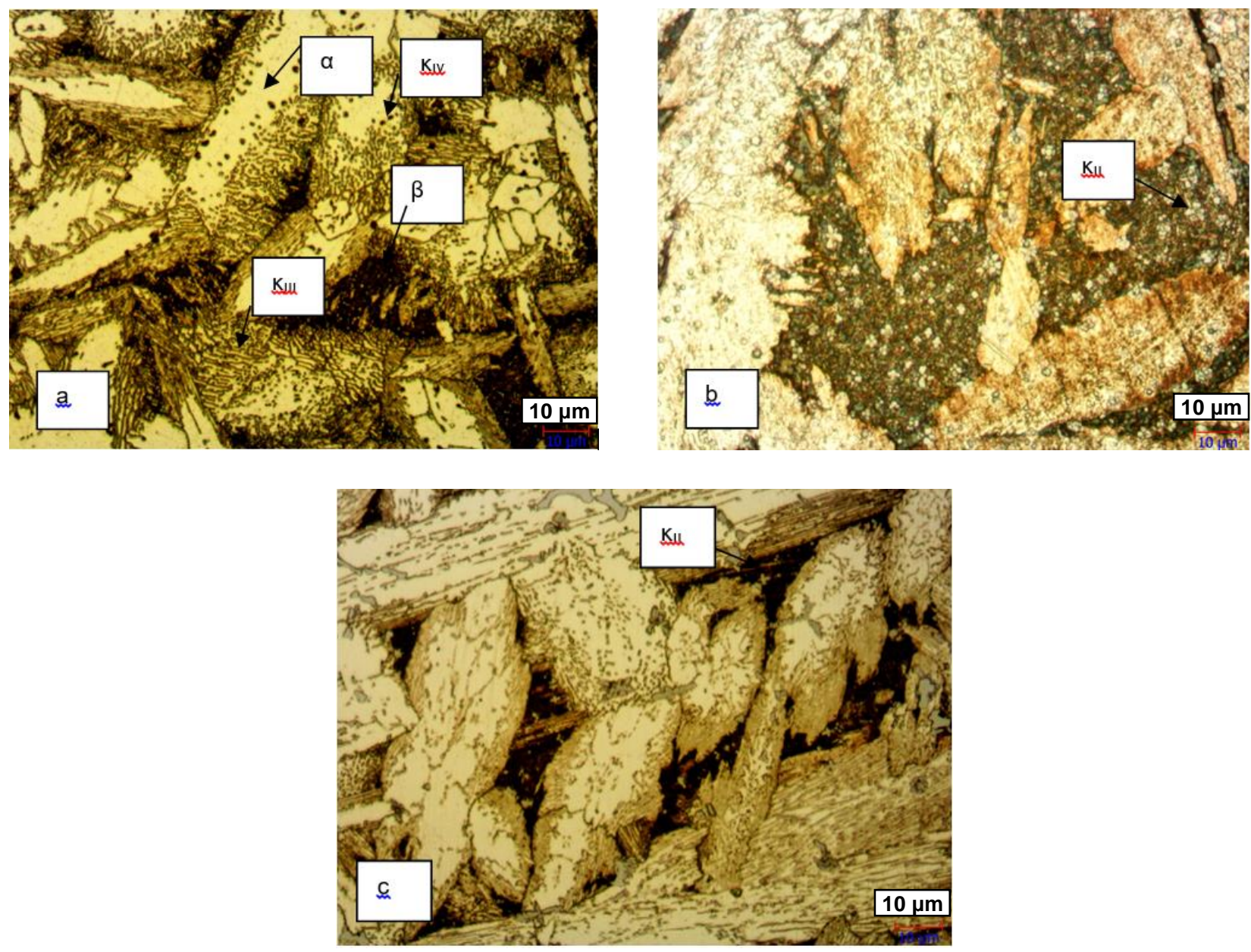

Figure 1 Optical micrographs of the as-cast condition of (a) Alloy 1, (b) Alloy 2 and (c) Alloy 3 
The smallest grain size value of $232 \mu \mathrm{m}$ was achieved for the $0.5 \mathrm{wt} \%$ cobalt containing alloy. The fact that titanium is much more effective in grain refinement of CuAl10Ni5Fe4 bronze was understood from the measurements.

One of the element-addition related grain refinement mechanisms is increase of the nucleation rate of an individual grain prior to increase in the number of grain nuclei. Smaller grains are formed as number of nucleation sites per unit volume increases [8]. The grain refining effect of cobalt and titanium addition is thought to be caused by generation of more nucleation sites leading to the formation of smaller grains.

Figure 1 and Figure 2 present microstructure photographs of the studied alloys in as-cast and forged conditions respectively. As-cast microstructure of Alloy 1, the photograph of which is given in Figure 1(a), represents the typical microstructure described in many studies about a nickel containing aluminum bronze. Copper-rich $\alpha$ (alpha) solid solution phase, martensitic $\beta$ (beta) phase and some intermetallic $\kappa$ (kappa) phases (fine $\kappa_{\mathrm{II}}$ and black spherical $\kappa_{\mathrm{iv}}$ ) were identified by the aid of the illustration given in Figure $3[9,10]$.
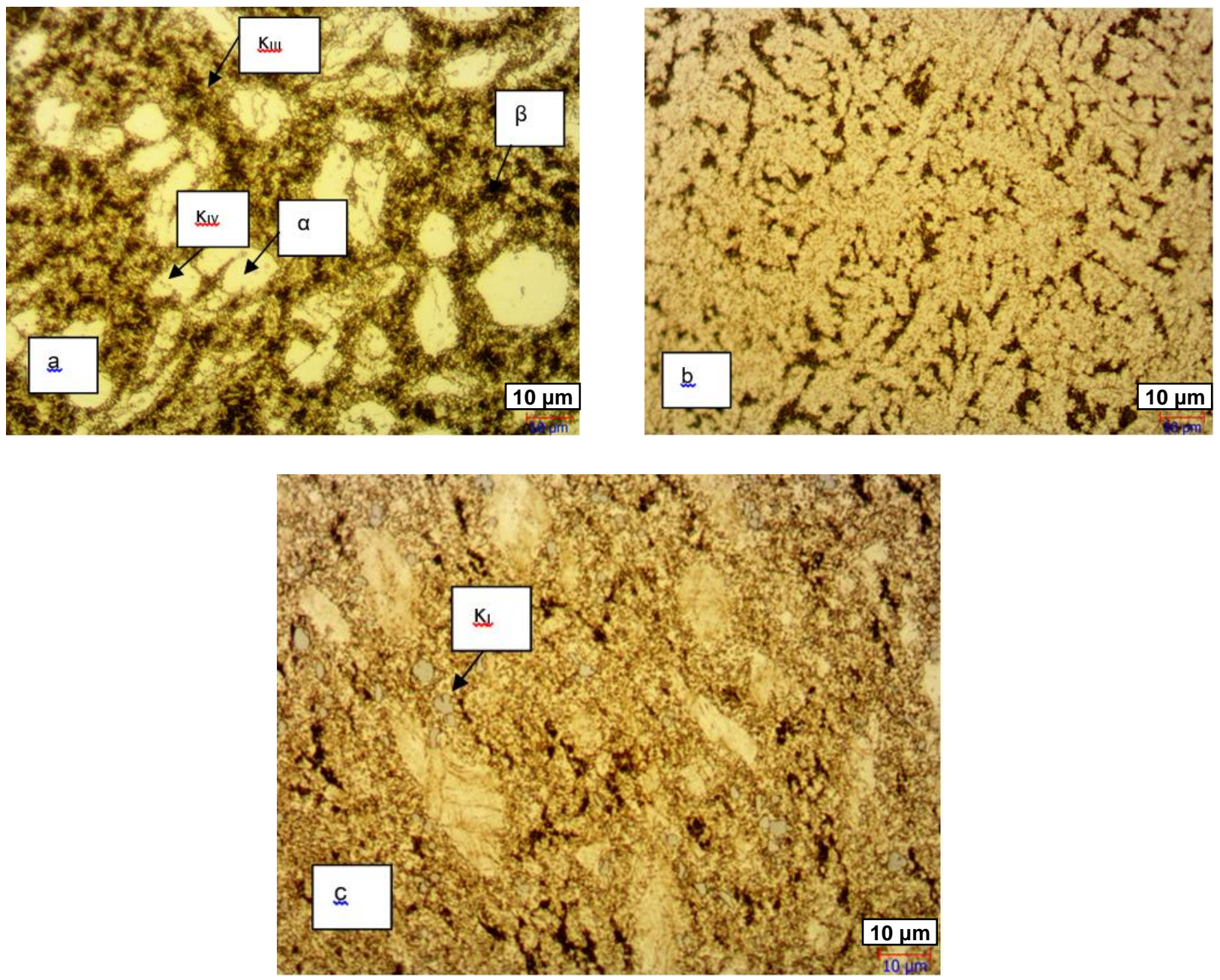

Figure 2 Optical micrographs of the forged condition of (a) Alloy 1, (b) Alloy 2 and (c) Alloy 3

Addition of cobalt and titanium to Alloy 1 in the content of $0.5 \%$, as seen in Figure 1(b) and 1(c), caused thinning of dendritic arms and an increase in the amount of some types of $\kappa$ phases; furthermore, a significant amount of $\kappa_{\| 1}$ phase precipitates were observed within the martensitic $\beta$ phase. On the other hand, as-cast microstructures of the alloys except Alloy 1 got considerably finer as a result of forging treatment. Forged Alloy 1 (Figure 2(a)) involves the same $\alpha, \beta$ and $\kappa$ phases as its as-cast condition. The dendritic arms broke off and 
became almost spherical while some new $\kappa_{\mathrm{iv}}$ phases precipitated because of the forging treatment. Apparent кı phases were visualised in the titanium-added alloy, as seen in the optical micrograph given in Figure 2(c). $\kappa_{\text {III }}$ phases were homogeneously distributed in the microstructure of both cobalt-added and titanium-added alloys. SEM examinations are needed in order to perform grain size analysis correctly in the case of forging. In future studies, SEM examinations of alloys will be made and microstructure components will be examined in more detail.

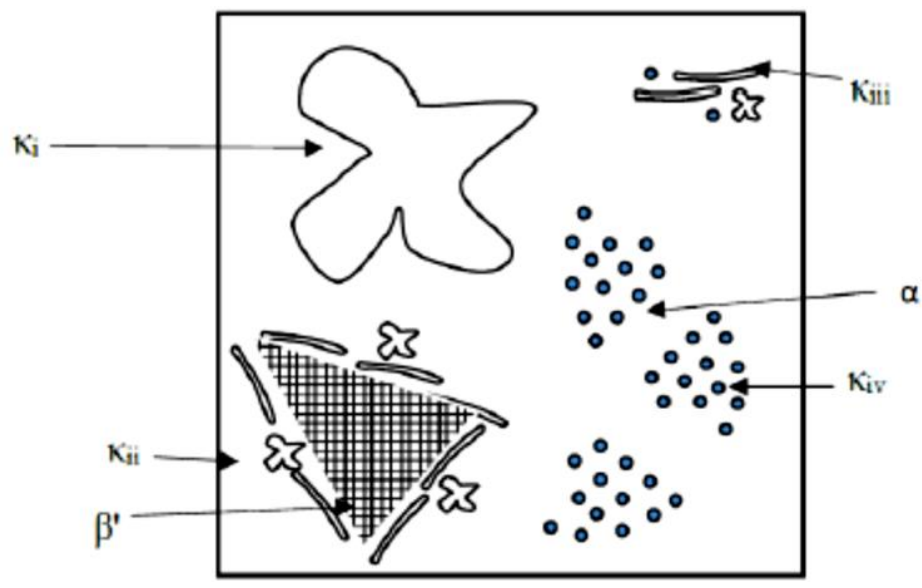

Figure 3 An illustration of the phases that are abundant in a nickel containing aluminum bronze

\subsection{Hardness measurements and tensile testing}

Results of Vickers microhardness measurements of as-cast and forged samples of each three alloys are presented in Table 3.

Table 3 Vickers microhardness measurement results of as-cast and forged samples of the alloys (load $1 \mathrm{~kg})$

\begin{tabular}{|c|c|c|}
\hline & \multicolumn{2}{|c|}{ Average hardness value $\left(\mathbf{H V}_{\mathbf{1}}\right)$} \\
\hline Sample & as-cast & forged \\
\hline Sample 1 & 200 & 256 \\
\hline Sample 2 & 195 & 274 \\
\hline Sample 3 & 189 & 280 \\
\hline
\end{tabular}

It was revealed that the as-cast hardness values of the three alloys were close to each other, the alloy without any grain refiner being slightly harder than the other two alloys. It is thought that the increase in the amount of martensitic $\beta$ and fine $\kappa_{\text {III, }}$ which are harder phases, was responsible for the increase of the as-cast hardness of this alloy.

While the forging treatment increased hardness of all the three alloys significantly, hardness values of Alloy 2 and Alloy 3 were measured close to each other, being higher than those of Alloy 1. Abundance of kappa phases improves the mechanical properties of nickel containing aluminum bronzes. Kappa phases, which were distributed homogeneously and the amount of which were higher in these two alloys than in Alloy 1 because of cobalt and titanium additions, led to the higher hardness of the two alloys.

When the difference of hardness values between the as-cast condition and the forged condition is considered, it is observed that the forging treatment increased the hardness of Alloy 3 most and that Alloy 1 was the one which was affected from the forging treatment least. This finding can be explained by more homogeneously distribution of dendritic arms after breaking as a result of the forging treatment which caused a higher hardness increase in the alloys with cobalt and titanium additions compared to the alloy without cobalt or titanium. 
Tensile testing results of the forged samples are given in Table 4. Cobalt and titanium which were added to the alloy in the amount of $0.5 \mathrm{wt} \%$ caused a significant increase especially in yield strength, but elongation value dropped as a result. Cobalt-added alloy exhibited the ideal values related to hardness measurement and tensile testing. Titanium addition decreased the elongation value of the alloy by more than $40 \%$.

Table 4 Tensile testing results of the forged samples of the three alloys

\begin{tabular}{|c|c|c|c|}
\hline Sample & Tensile strength (MPa) & Yield strength (MPa) & Elongation (\%) \\
\hline Sample 1 & 946 & 699 & 11.4 \\
\hline Sample 2 (Co) & 1077 & 799 & 10.0 \\
\hline Sample 3 (Ti) & 954 & 791 & 6.5 \\
\hline
\end{tabular}

\subsection{Potentiodynamic corrosion test}

After the completion of the potentiodynamic corrosion test that was conducted in the neutral solution containing $3.5 \% \mathrm{NaCl}$, corrosion rate values of the three alloys were calculated as given in Table $\mathbf{5}$. Among the forged samples of the three alloys, corrosion rate of Alloy 3 was the lowest while Alloy 2 and Alloy 1 exhibited higher values of corrosion rate in sequence.

The corrosion rates of cobalt-added Alloy 2 and titanium-added Alloy 3 which appeared to be lower than that of the alloy without grain refiner may be related to an increase in the amount of $\kappa_{\text {III }}$ phase, which is almost in a spherical shape; i.e. it can be claimed that a significant content of $\kappa_{111}$ phase led to an increase in corrosion resistance.

Table 5 Calculated corrosion rates of the forged samples of the alloys

\begin{tabular}{|c|c|}
\hline Sample & Corrosion rate (mm/year) \\
\hline Forged Sample 1 & 2.62 \\
\hline Forged Sample 2 & 2.51 \\
\hline Forged Sample 3 & 2.35 \\
\hline
\end{tabular}

\subsection{Abrasive Wear Test}

Measurement results of the wear test are given in Table 6. Addition of cobalt and titanium significantly increased the wear resistance of the alloy tested under a load of $40 \mathrm{~N}$. Wear test results are consistent with the corrosion rate calculations. Similar values of wear resistance were obtained for the cobalt-added alloy and the titanium-added alloy.

Table 6 Measured wear resistances of the forged samples of the alloys

\begin{tabular}{|c|c|}
\hline Sample & Wear area loss $\left(\mathbf{m m}^{2} / \mathbf{4 0} \mathbf{~ N}\right)$ \\
\hline Forged Sample 1 & 0.40 \\
\hline Forged Sample 2 & 0.23 \\
\hline Forged Sample 3 & 0.25 \\
\hline
\end{tabular}

\section{CONCLUSION}

This study involves an investigation of the effects of cobalt and titanium addition in the content of 0.5 wt $\%$ to a nickel-containing aluminum bronze (CuAl10Ni5Fe4 alloy). General results derived from the study are summarised below: 
1) Additions of cobalt and titanium caused a significant grain refinement in both as-cast and forged conditions.

2) While additions of cobalt and titanium did not change the hardness in as-cast conditions, they increased the hardness, tensile strength and yield strength in the forged conditions. However, grain refiner addition, especially titanium addition, decreased the elongation value considerably.

3) Additions of cobalt and titanium decreased also corrosion rate. The highest corrosion resistance was exhibited by the titanium-added alloy.

4) Wear resistances of the cobalt-added alloy and the titanium-added alloy were almost $50 \%$ higher than that of the alloy without any grain refiner.

\section{REFERENCES}

[1] TAN, Z., GUO, Q., ZHAI, W., ZHAO, Z. Tribological characteristics of nickel-aluminium bronze CuAl10Ni5Fe4 against 30CrMnSiA steel after the prior corrosion treatment. Applied Mechanics and Materials. 2012, vol. 201202, pp. 73-77.

[2] MEIGH, H. Cast and wrought aluminum bronzes: Properties, processes and structure. Copper Development Association. 2008, Edition No:1, Hanover, UK.

[3] RICHARDSON, I. Guide to nickel aluminum bronze for engineers. Copper Development Association. Publication no. 222, 2016.

[4] JAHANAFROOZ, A., HASAN, F., LORIMER, G.W., RIDLEY, N. Microstructural development in complex nickelaluminum bronze. Metall. Trans. A. 1983, vol. 14A, pp. 1951-1956.

[5] LI, YUAN, NGAI, T.L. Grain refinement and microstructural effects on mechanical and tribological behaviours of Ti and B modified aluminum bronze. Second Department of Mechanical Engineering, South China University of Technology, Guangzhou, People's Republic of China. Journal of Materials Science. 1996, vol. 31, pp. 5333-5338.

[6] LI, W. S., WANG, Z. P., LU, Y., YUAN, L. H., XIAO R. Z., ZHAO X. D. Corrosion and wear behaviors of AIbronzes in $5.0 \% \mathrm{H}_{2} \mathrm{SO}_{4}$ solution. Trans. Nonferrous Met. Soc. China. 2009, vol. 19, pp. 311-318.

[7] ASTM Standard, G102-89. Standard practice for calculation of corrosion rates and related information from electrochemical measurements. 2015, e1.

[8] DAROONPARVAR, M.R., ATABAKI, M. M., VAKILIPOUR, A. Effect of pre-heat treatment on corrosion behavior of nickel-aluminum bronze alloy. Metalurgija-MjoM. 2011, vol. 17, iss. 4, pp. 183-198.

[9] YASEEN, M. K., MANSOOR, M., ANSARI, H. A., HUSSAIN, S., KHAN, S. Effect of heat treatment on tribological characteristics of CuAl10Ni5Fe4 nickel aluminum bronze. Key Engineering Materials. 2018, vol. 778, pp 61-67.

[10] DING, Y., LV, Y., CHEN, K., ZHAO, B., HAN, Y., WANG, L. Effects of microstructure on the stress corrosion cracking behavior of nickel aluminum bronze alloy in $3.5 \% \mathrm{NaCl}$ solution. Materials Science \& Engineering $\mathrm{A}$. 2018, vol. 733, pp. 361-373.

[11] ASTM G99. Standard test method for wear testing with a pin-on-disk apparatus. ASTM International. 